\title{
General joint hypermobility and temporomandibular joint derangement
} in adolescents

\author{
Lilian Westling, Agneta Mattiasson
}

\begin{abstract}
Joint mobility was assessed in each member of an epidemiological sample of 96 girls and 97 boys, 17 years old, and graded by means of the hypermobility score of Beighton et al. Twenty two per cent of the girls and $3 \%$ of the boys could perform five or more of the nine manoeuvres. The prevalence of symptoms and signs of internal derangement in the temporomandibular joint was higher in adolescents with hypermobility of joints (score $\geqslant 5 / 9$ ). In subjects with a high mobility score oral parafunctions (overuse) correlated more strongly with several signs and symptoms of craniomandibular disorder than in those with a low score.
\end{abstract}

The term 'hypermobility syndrome' has been used to describe articular complaints that arise in hypermobile subjects in the absence of a defined rheumatic disease. ${ }^{1-5}$

Significant correlations between benign hypermobility of joints and internal derangement of the temporomandibular joint (TMJ) have been reported. ${ }^{6-8}$ In a randomly selected group of female patients with craniomandibular disorders $83 \%$ with a score of 3 or more on the Beighton nine point scale ${ }^{9}$ had derangement of the TMJ in comparison with $41 \%$ of the patients with a score between 0 and $2(p<0.001){ }^{7}$

Internal derangement of the TMJ is a condition in which the articular disc is intermittently or permanently dislocated. ${ }^{10}$ In the early stages of internal derangement a clicking sound occurs during mandibular movements when the condyle slips over the posterior edge of an anteriorly or medially dislocated disc. At later stages of the condition the disc may be caught between the articular eminence and the condyle (an acute lock of the mandible), or the disc may be permanently dislocated anteriorly, thus restricting mouth opening ability. Dislocation of the disc is associated with a disturbed relation between the condyle and the fossa. Physiological as well as parafunctional forces will be applied on the posterior highly vascularised and innervated part of the TMJ instead of on the dense cartilaginous collagenous connective tissue. Crepitation sounds in the TMJ are often correlated with degenerative joint disease (osteoarthritis), which in about $90 \%$ of cases is preceded by disc derangement. ${ }^{11}$

Temporomandibular joint sounds are the most common signs of craniomandibular disorder. ${ }^{12}$ Epidemiological studies of the stomatognathic system show that between 15 and $35 \%$ of the population are aware of TMJ sounds. ${ }^{12}$ In patients with craniomandibular disorder the incidence of sounds is $45-80 \% .^{12}$ Correlations between joint sounds and other signs and symptoms of craniomandibular disorder have been shown in epidemiological studies ${ }^{13-15}$ and in patient studies. ${ }^{16}$ Temporomandibular joint clicking may imply a pathological condition, such as internal disc derangement, or may be a variation of the normal anatomical features of the TMJ. Little research has been carried out into the role of these factors in the development of pain and dysfunction.

This investigation is aimed at discerning TMJ sounds in an adolescent non-patient group and at correlating the different sounds with craniomandibular symptoms and signs and with inherited general joint laxity.

\section{Subjects and methods}

SUBJECTS

The subjects comprised an epidemiological sample of 96 girls and 97 boys, 17 years old, living in an urban district on the west coast of Sweden. Details of the group have been given earlier. ${ }^{17}$ Before physiological examination of the masticatory system each teenager was given a questionnaire. The questions about symptoms indicating TMJ problems, pain in other joints, and awareness of oral parafunctions could be answered by 'frequently', 'occasionally', or 'no'. The questions about occurrence of headache once or more a week and occurrence of trauma to the head and jaws had to be answered by 'yes' or 'no'. ${ }^{17}$ All adolescents were clinically examined by examiner $\mathrm{A}$ before any information about their history was obtained. No radiographic investigation of the TMJ was performed.

\section{EVALUATION OF TEMPOROMANDIBULAR JOINT}

\section{SOUNDS}

Temporomandibular joint sounds were evaluated by auscultation and manual palpation during vertical opening and closing movements of the mandible. The clicking pattern was related to the interincisal distance and categorised as reciprocal clicking, non-reciprocal clicking, or late opening clicking. In reciprocal clicking the click at mandibular opening is louder than the click at closing and occurs at a point of greater condylar translation. ${ }^{10}$ Reciprocal clicking may be a sign of internal derangement of the TMJ. ${ }^{10}{ }^{18}$ Non-reciprocal clicking occurs usually only at mandibular closing or, when occurring both at opening and closing, the sounds are of about the same intensity and at the same 
interincisal distance. Non-reciporcal clicking is said to occur, for example, when the condyle moves over a static obstacle. ${ }^{18}$ Late clicking occurs when the disc and condyle pass the tubercle at the end of the mandibular translation phase. ${ }^{19}$

The TMJ was palpated for tenderness in the external auditory meatus during functional movements of the mandible.

\section{JOINT MOBILITY EXAMINATION}

Joint mobility was assessed in each subject and graded by the hypermobility score of Beighton et al. ${ }^{9}$ The scoring system is as follows: $(a)$ passive dorsiflexion of the little fingers beyond $90^{\circ}$ (one point for each hand)-two points; $(b)$ passive apposition of the thumbs to the flexor aspects of the forearm (one point for each thumb)-two points; $(c)$ hyperextension of the elbows beyond $10^{\circ}$ (one point for each elbow)two points; $(d)$ hyperextension of the knees beyond $10^{\circ}$ (one point for each knee)-two points; $(e)$ forward flexion of the trunk with the knees fully extended so that the palms of the hands rest flat on the floor-one point. The maximum score is nine. All adolescents were examined for general joint mobility by examiner $B$ and before any information about their history or clinical signs was obtained.

\section{STATISTICS}

Differences between joint mobility groups and between girls and boys were tested for statistical significance with the Mann-Whitney U test. Correlations between TMJ sounds and symptoms and signs were analysed with the Spearman rank correlation test. Comparison of prevalences was tested by the $\chi^{2}$ test with Yates's continuity correction.

\section{Results}

\section{JOINT MOBILITY}

Joint mobility scores of 0 to 4 were evenly distributed between girls and boys, but for the highest scores the girls were dominant. The 90th centile range of movement was $5 / 9$ for the whole group and for the girls, and $4 / 9$ for the boys. Twenty eight per cent of the girls and $21 \%$ of the boys could perform four or more of the manoeuvres (NS). Twenty two per cent of the girls and $3 \%$ of the boys had a Beighton score of $\geqslant 5 / 9(p<0.001)$.

Subjects who could perform five or more of the manoeuvres evaluated their symptoms of craniomandibular disorder as more severe

Table 1 Percentage distribution of temporomandibular joint (TMF) sounds

\begin{tabular}{lll}
\hline TMf sound & $\begin{array}{l}\text { Girls } \\
(n=96)\end{array}$ & $\begin{array}{l}\text { Boys } \\
(n=97)\end{array}$ \\
\hline Reciprocal clicking & 19 & 16 \\
Non-reciprocal clicking & 7 & $21^{* *}$ \\
Late clicking & 5 & 1 \\
Crepitation & 1 & 0 \\
TMJ sounds (total) & 32 & 34 \\
\hline${ }^{* *} \mathrm{p}<0.01$. & &
\end{tabular}

Table 2 Percentage distribution of temporomandibular joint (TMF) sounds in 193 adolescents with different degrees of general joint mobility

\begin{tabular}{|c|c|c|c|c|}
\hline \multirow[t]{2}{*}{ TMF sounds } & \multicolumn{4}{|c|}{ foint mobility score } \\
\hline & $\begin{array}{l}0-3 \\
(n=146)\end{array}$ & $\begin{array}{l}\geqslant 4 \\
(n=47)\end{array}$ & $\begin{array}{l}0-4 \\
(n=169)\end{array}$ & $\stackrel{\geqslant 5}{(n=24)}$ \\
\hline $\begin{array}{l}\text { Reciprocal clicking } \\
\text { Non-reciprocal clicking } \\
\text { Late clicking }\end{array}$ & $\begin{array}{r}14 \\
14 \\
3\end{array}$ & $\begin{array}{l}30^{*} \\
15 \\
2\end{array}$ & $\begin{array}{r}15 \\
15 \\
3\end{array}$ & $\begin{array}{l}38^{* *} \\
4 \\
4\end{array}$ \\
\hline
\end{tabular}

$(p<0.001)$ than those whose score was less than five. When signs and symptoms in adolescents with a score $\geqslant 4 / 9$ were evaluated no difference was found between boys and girls.

TEMPOROMANDIBULAR JOINT SOUNDS AND SEX

Temporomandibular joint sounds were noted in more than $30 \%$ of the adolescents (table 1 ). Thirty eight per cent of all joint sounds were noticed in the right joint and $62 \%$ in the left joint. The prevalence was about the same in the girls as in the boys with the exception of nonreciprocal clicking, which was significantly more common in the boys $(p<0.01)$. Crepitation was noted in one girl. She reported several TMJ pain symptoms and frequent growing pains but no trauma to the jaws. About $25 \%$ had sounds in one joint, $4 \%$ of the girls and $10 \%$ of the boys had sounds in both TMJs. In four boys reciprocal clicking was evaluated in one joint and non-reciprocal clicking in the other.

\section{TEMPOROMANDIBULAR JOINT SOUNDS AND JOINT} LAXITY

When the prevalence of different TMJ clicking was analysed in groups with different mobility scores only the prevalence of reciprocal clicking showed significant differences (table 2). About $30 \%$ of both girls and boys with a mobility score $\geqslant 4 / 9$ had reciprocal clicking, which was significantly more than in adolescents with a lower score $(p<0.05)$. The difference was even more significant when those with a mobility score $\geqslant 5 / 9$ were compared with the other boys and girls $(p<0.01)$. Three boys had a score $\geqslant 5 / 9$; two of them had reciprocal clicking.

\section{TEMPOROMANDIBULAR JOINT SOUNDS AND} REPORTED SYMPTOMS

Table 3 presents the correlations between different TMJ sounds and symptoms of craniomandibular disorder, reported in the questionnaire. The correlations were made between subjects with only one type of sound and those with no TMJ sound. The subjective awareness of joint sounds was about the same in the three groups of clinically observed clickings. Seven girls reported intermittent locking of the mandible. Four of these girls had reciprocal clicking at the clinical examination and reported several other symptoms of dysfunction. For three of them the mobility score was $5 / 9$, and for one $0 / 9$. The last girl had a head trauma in her history. 
Table 3 Significant $(p<0.01)$ correlation coefficients between clinically demonstrable temporomandibular joint (TMY) sounds and self reported symptoms of craniomandibular disorder in 193 adolescents

\begin{tabular}{lllll}
\hline Symptom & $\begin{array}{l}R C^{*} \\
(n=30)\end{array}$ & $\begin{array}{l}N R C^{*} \\
(n=23)\end{array}$ & $\begin{array}{l}L C^{*} \\
(n=6)\end{array}$ & $\begin{array}{l}\text { No TMF sound } \\
(n=129)\end{array}$ \\
\hline $\begin{array}{l}\text { Difficulty in opening mouth wide } \\
\text { Pain on movement of the jaw }\end{array}$ & $\begin{array}{l}0.30 \\
0.21\end{array}$ & & & -0.28 \\
Chewing difficulties & 0.29 & & 0.28 & -0.25 \\
Joint sounds & 0.30 & 0.31 & 0.38 & -0.38 \\
Locking of the mandible & 0.24 & & & -0.22 \\
Anamnestic index & 0.28 & & 0.34 & -0.34 \\
\hline
\end{tabular}

${ }^{*} \mathrm{RC}=$ reciprocal clicking; $\mathrm{NRC}=$ non-reciprocal clicking; $\mathrm{LC}=$ late clicking; -indicates negative relation.

Table 4 Significant $(p<0 \cdot 01)$ correlation coefficients between temporomandibular joint (TMF) sounds and clinical signs in 193 adolescents

\begin{tabular}{|c|c|c|c|}
\hline Sign & $\begin{array}{l}R C^{*} \\
(n=30)\end{array}$ & $\begin{array}{l}N R C^{*} \\
(n=23)\end{array}$ & $\begin{array}{l}L C^{*} \\
(n=6)\end{array}$ \\
\hline $\begin{array}{l}\text { Posterior TMJ tenderness at } \\
\text { mandibular movement } \\
\text { Pain on movement }\end{array}$ & $\begin{array}{l}0.41 \\
0.28\end{array}$ & & \\
\hline $\begin{array}{l}\text { Deviation or irregular movement } \\
\text { of mandible, or both } \\
\text { Attrition of anterior teeth }\end{array}$ & 0.46 & 0.24 & 0.24 \\
\hline
\end{tabular}

TEMPOROMANDIBULAR JOINT SOUNDS AND CLINICAL SIGNS

Table 4 presents correlations between different TMJ sounds and clinical signs of craniomandibular disorder. Temporomandibular joint tenderness and pain only correlated with reciprocal clicking. Non-reciprocal clicking correlated significantly with obvious signs of attrition of anterior teeth.

\section{EXCESSIVE LOADINC}

No correlation was found between excessive loading of the $T M J$, as in reported frequent teeth clenching and grinding and reciprocal clicking. More correlations between frequent oral parafunction and TMJ pain dysfunction were found in subjects with reciprocal clicking, however, than in the other adolescents (table 5).

\section{Discussion}

The significant correlations found in this investigation of an adolescent non-patient group between general joint hypermobility and signs of internal derangement of the TMJ indicate a systemic cause. Internal derangement of the TMJ is a common finding in patients with severe pain and dysfunction at craniomandibular disorder clinics. ${ }^{7820}$ In a recent study of female patients with craniomandibular disorder about $20 \%$ of the patients reported daily headache, and of those with the diagnosis of TMJ osteo-

Table 5 Significant $(p<0.01)$ correlation coefficients between frequent teeth clenching or grinding, or both, and self reported symptoms of craniomandibular disorder in adolescents with and without clinically demonstrable temporomandibular joint (TMF) sounds

\begin{tabular}{llll}
\hline Symptom & $\begin{array}{l}R C^{*} \\
(n=34)\end{array}$ & $\begin{array}{l}N R C^{*} \\
(n=23)\end{array}$ & $\begin{array}{l}\text { No TMf } \\
(n=129)\end{array}$ \\
\hline $\begin{array}{l}\text { Difficulty in opening mouth wide } \\
\text { Pain on movement of the jaw }\end{array}$ & $\begin{array}{l}0.58 \\
\text { Tiredness during chewing }\end{array}$ & 0.53 & 0.27 \\
$\begin{array}{l}\text { Locking of the mandible } \\
\text { Anamnestic index }\end{array}$ & $\begin{array}{l}0.68 \\
0.37\end{array}$ & 0.69 & 0.47 \\
\hline
\end{tabular}

arthritis, $33 \%$ had a headache every day. ${ }^{8}$ No correlations between signs and symptoms of internal derangement and recurrent headache were found in this study of a non-patient group.

The occurrence of reciprocal clicking in this investigation did not merit the diagnosis 'internal derangement' in every case because of the design of the study. The pattern of correlations between reciprocal clicking and signs and symptoms in the participants of this study, however, indicates a relation between reciprocal clicking and TMJ disorder. Thus, for example, the four girls who reported intermittent locking of the mandible and several other symptoms of dysfunction, and had reciprocal clicking at the clinical examination, had positive criteria of internal derangement. Several subjective symptoms of pain and dysfunction correlated significantly with reciprocal clicking, a few with late clicking, and none, except an awareness of joint sounds, with non-reciprocal clicking (table 3).

This study showed that general hypermobility seemed to have an important role in developing TMJ pain and dysfunction, even in young people, particularly when their joints were exposed to excess loading as in oral parafunctions. This investigation found no indication that oral parafunctions generally produce TMJ dysfunction, which is in agreement with other studies. ${ }^{821}$

The correlations in this study between nonreciprocal clicking and tooth attrition may show a reaction of the TMJ cartilage on local loading, which was not indicated by the questionnaire about oral habits.

Radiography has indicated the presence of hypermobility of the TMJ with the condyle in a position anterior and inferior to the articular tubercle. ${ }^{22} \mathrm{~A}$ recent double contrast arthrotomographic investigation classified TMJ hypermobility more precisely as occurring when the condylar translation exceeds the insertion of the anterior TMJ capsule on the temporal bone. ${ }^{23}$ Radiographic methods can hardly be used for epidemiological purposes, however, and were not used in this study.

Previous reports found weak correlations between linear measurements of mandibular border positions and peripheral joint mobility measurements. ${ }^{24} 25$ The linear measurement usually obtained, of maximal active mandibular movement as the interincisal distance in the median plane, is dependent on the length of the jaw. ${ }^{26} \mathrm{~A}$ recent study of healthy adolescents found significant correlations between mandibular opening ability and general joint mobility by measuring angular rotation of the mandible at maximum jaw opening. ${ }^{26 a}$

The possibility of a causal relation between osteoarthritis and internal derangement has been discussed. ${ }^{11}$ Histopathological alterations of the TMJ articular cartilage have been found in young subjects often accompanied by disc displacement. ${ }^{27}$ It has been claimed ${ }^{28}$ that osteoarthritic changes of the articular surfaces, such as fibrillation, cause roughness of the condylar cartilage as well as of the disc and the articular eminence. The roughness increases the friction between the articular components. It is 
likely that a connective tissue structure contributing to a lax capsule, together with increased friction between the articular components of the TMJ, is the main factor in the genesis of internal derangement, which may be an early clinical sign of osteoarthritis.

\section{Conclusion}

An inherited factor, general joint hypermobility, which was more prevalent in female than in male subjects, was in this investigation of an adolescent non-patient group correlated with symptoms and signs of internal derangement in the TMJ. This factor may be one explanation for the predominance of female subjects among patients with craniomandibular disorder.

Internal derangement (disc displacement) of the temporomandibular joint may be regarded as a symptom of the joint hypermobility syndrome.

1 Kirk J A, Ansell B M, Bywaters E G L. The hypermobility syndrome. Musculoskeletal complaints associated with generalized joint hypermobility. Ann Rheum Dis 1967; 26: generalized.

2 Scharf Y, Nahir A M. Hypermobility syndrome mimicking juvenile chronic arthritis. Rheumatol Rehabil 1982; 21 78-80.

3 Biro F, Gewanter H L, Baum J. The hypermobility syndrome. Pediatrics 1983; 72: 701-6.

4 Gedalia A, Person D A, Brewer E J, Giannini E H. Hypermobility of the joints in juvenile episodic arthritis/ arthralgia. F Pediatr 1985; 107: 873-6.

5 Arroyo I L, Brewer E J, Giannini E H. Arthritis/arthralgia and hypermobility of the joints in schoolchildren. f Rheumatol 1988; 15: 978-80.

6 Bates R E, Stewart C M, Atkinson W B. The relationship between internal derangements of the temporomandibular joint and systemic joint laxity. F Am Dent Assoc 1984; 109: 446-7.

7 Westling L. Craniomandibular disorders and general joint mobility. Acta Odontol Scand 1989; 47: 293-9.

8 Westling L, Carlsson G E, Helkimo M. Background factors in craniomandibular disorders: with special reference to general joint hypermobility, parafunction and trauma. general joint hypermobility, parafunction and trauma.

9 Beighton P, Solomon L, Soskolne C L. Articular mobility in an African population. Ann Rheum Dis 1973; 32: 413-8.

10 Solberg $W \mathrm{~K}$. Temporomandibular disorders: managemen of internal derangement. $\mathrm{Br}$ Dent $\mathcal{F} 1$ 1986; 160: 379-85.

11 Westesson P-L, Rohlin M. Internal derangement related to osteoarthrosis in temporomandibular joint autopsy speciosteoarthrosis in temporomandibular joint autopsy speci-
mens. Oral Surg Oral Med Oral Pathol 1984; 57: 17-22.
12 Wabeke K B, Hansson T L, Hoogstraten J, van der Kuy P. Temporo-mandibular joint clicking: a literature overview. Fournal of Craniomandibular Disorders 1989; 3: 163-73.

13 Nilner M. Epidemiology of functional disturbances and diseases in the stomatognathic system. A cross-sectional study of 7-18 year olds from an urban district. Swed Dent $f$ 1983; (suppl 17).

14 Wänman A, Agerberg G. Relationship between signs and symptoms of mandibular dysfunction in adolescents. Community Dent Oral Epidemiol 1986; 14: 225-30.

15 Nielsen L, Melsen B, Terp S. Prevalence, interrelation, and severity of signs of dysfunction from masticatory system in 14-16-year-old Danish children. Community Dent Oral Epidemiol 1989; 17: 91-6.

16 Wedel A, Carlsson G E. Analysis of functional disturbances of the masticatory system. Foumal of Craniomandibular Practice 1984; 2: 350-7.

17 Westling L, Mattiasson A. Background factors in craniomandibular disorders: reported symptoms in adolescents with special reference to joint hypermobility and oral parafunctions. Scand 7 Dent Res. 1991; 99: 48-54.

18 Isberg-Holm A, Westesson P-L. Movement of disc and condyle in temporomandibular joints with clicking. An arthrographic and cineradiographic study on autopsy specimens. Acta Odontol Scand 1982; 40: 153-66.

19 Pullinger A G, Seligman D A, Solberg W K. Temporomandibular disorders. Part I: Functional status, dentomorphologic features, and sex differences in a nonpatient population. F Prosthet Dent 1988; 59: 228-35.

20 Isacsson G, Isberg A, Johansson A-S, Larsson O. Internal derangement of the temporomandibular joint: radiographic and histologic changes associated with severe pain. $\mathcal{F}$ Oral Maxillofac Surg 1986; 44: 771-8.

21 Marbach J J, Lennon M C, Dohrenwend B P. Candidate risk factors for temporomandibular pain and dysfunction syndrome: psychosocial, health behavior, physical illness and injury. Pain 1988; 34: 139-51.

22 Meng H P, Dibbets J M H, van der Weele L Th, Boering G. Symptoms of temporomandibular joint dysfunction and predisposing factors. F Prosthet Dent 1987; 57: 215-22.

23 Johansson-Garnier A S. Temporomandibular joint internal derangement. Tissue reactions and topographical relations with implication on pain. Stockholm: Karolinska Institutet, 1990. (Thesis.)

24 Agerberg G. Maximal mandibular movements in teenagers. Acta Morphol Neerl Scand 1974; 12: 79-102.

25 McCarroll R S, Hesse J R, Naeije M, Yoon C K, Hansson T L. Mandibular border positions and their relationship with peripheral joint mobility. F Oral Rehabil 1987; 14: with perip

26 Wright $\mathbf{V}$, Hopkins $R$. The temporo-mandibular joint: measurement of joint movement. Clin Rheum Dis 1982; 8: 715-22.

26a Westling L, Helkimo E. Maximum jaw opening capacity in adolescents in relation to general joint mobility. $F$ Oral Rehabil. In press.

27 Lubsen C C, Hansson T L, Nordström B B, Solberg W K. Histomorphometric analysis of cartilage and subchondral bone in mandibular condyles of young human adults at autopsy. Arch Oral Biol 1985; 30: 129-36.

28 Bont L G M de, Boering G, Liem R S B, Havinga P. Osteoarthritis of the temporomandibular joint: a light microscopic and scanning electron microscopic study of the articular cartilage of the mandibular condyle. Int $\mathcal{F}$ Oral Maxillofac Surg 1985; 43: 481-8. 